\title{
INTERthesis
}

DOUTORADO INTERDISCIPLINAR EM CIÊNCIAS HUMANAS - UFSC - FLORIANÓPOLIS - SC - BRASIL

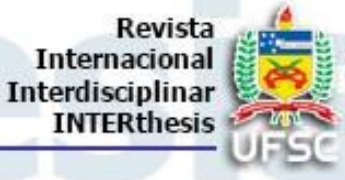

\section{DESEMPREGO, JUVENTUDE E CRISE ESTRUTURAL DO CAPITAL: 0 PRECARIADO NA CENA CONTEMPORÂNEA}

\author{
Hellen Bastos Gomes ${ }^{1}$ \\ Selma Suely de Oliveira Baçal ${ }^{2}$ \\ Márcia Irene Pereira Andrade ${ }^{3}$
}

\section{Resumo:}

Discutir acerca do conceito precariado não é modismo. Trata-se de um debate sobre o entendimento da geopolítica do capital em tempos de crise e de conflito potencial. Com base em autores como István Mészáros (2009), Giovani Alves (2007, 2012, 2013), Mandel (1990) entre outros. Destaca-se que o objetivo deste artigo é refletir sobre a relação entre a expansão do ensino superior, crise estrutural do capital e suas implicações na visibilidade do precariado. A metodologia utilizada é de caráter qualitativo, a partir de análise documental e resultados de pesquisa empírica, com vistas a indicar a premência em se discutir acerca do precariado e sua relação com a expansão da educação superior no Brasil num contexto de crise estrutural do capital e neoliberalismo. Os resultados, apontam como tendência que o processo expansionista da educação superior no atual momento histórico mais do que se constituir em uma possibilidade de emancipação humana, encontra-se sob a regência do capital e se transmuta em uma mercadoria barata, de fácil consumo e de pouco conteúdo, e isso se espraia dessa forma em todos os níveis do sistema de ensino brasileiro cuja visibilidade reside no precariado.

Palavras-chave: Crise estrutural. Educação Superior. Precariado.

\section{UNEMPLOYMENT, YOUTH AND STRUCTURAL CRISIS OF CAPITAL: THE PRECARIOUS ON THE CONTEMPORARY SCENE}

\begin{abstract}
:
Discussing the precarious concept is not a fad. It is a debate about understanding the geopolitics of capital in times of crisis and potential conflict; we say that based on authors such as István Mészáros (2009), Giovani Alves (2007, 2012, 2013), Mandel (1990), Standing (2015), and others. It should be pointed out that the purpose of this

\footnotetext{
${ }^{1}$ Doutoranda em Educação na Universidade Federal do Amazonas, Manaus. Assistente Social do Programa Observatório dos Direitos da Criança e Adolescente. Professora de Serviço Social Universidade Nilton Lins, Manaus, AM, Brasil E-mail: hellenbastosgomes@hotmail.com

${ }^{2}$ Doutora em Educação pela Universidade de São Paulo. Professora Titular no Curso de Licenciatura Plena em Pedagogia e no Programa de Pós-Graduação em Educação da Universidade Federal do Amazonas, Manaus, AM, Brasil E-mail: selmabacal@ufam.edu.br

${ }^{3}$ Doutora em Educação pela Universidade Federal do Amazonas, Professora do Curso de Serviço Social na mesma Universidade. Coordenadora do Programa de Extensão: Observatório dos Direitos da Criança e do Adolescente em Manaus, AM, Brasil marciamavignier01@gmail.com
} 
article is to reflect on the relationship between the expansion of higher education, the structural crisis of capital and its implications on the visibility of the precarious. The methodology used is qualitative, based on documentary analysis and results of empirical research, aiming to indicate the urgency to discuss the precariousness and its relation with the expansion of higher education in Brazil in a context of structural crisis of capital and neoliberalism. The results show that the expansionist process of higher education in the present historical moment, rather than being a possibility of human emancipation, is under the rule of capital and transformed into cheap, easy-touse and cheap merchandise content and this is spreading this way in all levels of the Brazilian education system whose visibility lies in the precarious.

Keywords: Structural Crisis. College education. Precarious.

\section{DESEMPLEO, JUVENTUD Y CRISIS ESTRUCTURAL DEL CAPITAL: LO PRECARIO EN LA ESCENA CONTEMPORÁNEA.}

\section{Resumen:}

Discutir el concepto precariado no es una moda pasajera. Es un debate sobre la comprensión de la geopolítica del capital en tiempos de crisis y conflicto potencial, basado en autores como István Mészáros (2009), Giovani Alves (2007, 2012, 2013), Mandel (1990), Standing (2015), entre otros. Cabe señalar que el propósito de este artículo es reflexionar sobre la relación entre la expansión de la educación superior, la crisis estructural del capital y sus implicaciones sobre la visibilidad de la precariedad. La metodología utilizada es cualitativa, a partir del análisis de documentos y resultados de investigaciones empíricas, con el fin de indicar la urgencia de la discusión sobre el precariado y su relación con la expansión del educación superior en Brasil en el contexto de crisis estructural del capital y neoliberalismo. Los resultados apuntan a una tendencia de que el proceso de expansión de la educación superior en el momento histórico actual más que constituir una posibilidad para la emancipación humana está bajo el dominio del capital y se transforma en un producto barato, fácil de usar y de poco contenido, y esto se está difundiendo de esta manera en todos los niveles del sistema educativo brasileño, cuya visibilidad reside en lo precario.

Palabras clave: Crisis estructural. Educación universitaria. Precariado. 


\section{INTRODUÇÃO}

A crise estrutural do capital promove modificações profundas em nossa sociedade. O capitalismo na contemporaneidade exige a reorganização da gestão do trabalho, do Estado e do mercado, pois o contexto atual expressa à dinâmica da precarização em todas as esferas da vida social.

A expansão da educação superior a partir do século XXI e a visibilidade do precariado 4 necessita ser problematizada, pois, a "geopolítica do capital em crise" (CARVALHO \& GUERRA, 2015) requer capturar a educação como mercadoria rentável, bem como se configura como o fio condutor do processo de desenvolvimento que prima pela "padronização" do trabalho, visto que a "introdução de novas tecnologias é um terreno extremamente fértil para promover a denominada captura da subjetividade do trabalhador" (NASCIMENTO, GUERRA \& TRINDADE, 2016, p.4). Por isso, a necessidade de uma "reengenharia" educacional.

Andrade (2017) corrobora com esse entendimento e afirma que a educação deve ser concebida como um direito social. Em se tratando do Brasil, materializar tal direito é obstaculizado por um arranjo neoliberal, visto como elemento ideopolítico da crise estrutural do capital, que apresenta traços marcantes a partir da década de 1990 no governo de Fernando Henrique Cardoso - FHC (1995-2002), e aprofundou-se no governo de Luís Inácio Lula da Silva (2003 a 2010), com forte continuidade no governo de Dilma Vana Rousseff (2011 a 2016), provocando uma (re)organização da política educacional brasileira sob a lógica dos organismos financeiros internacionais.

Tal convicção reside ainda quando se apreender a crise estrutural do capital como parte constitutiva do próprio modo de produção capitalista, que "vai se tornar a certa altura muito mais profunda, no sentido de invadir não apenas o mundo das finanças globais mais ou menos parasitárias, mas também todos os domínios da vida social, econômica e cultural" (MÉSZÁROS, 2009, p. 17).

Os dados do Censo da Educação Superior (2016) apontam que das 2.407 (duas mil, quatrocentos e sete) Instituições de Ensino Superior, 2.111 (duas mil, cento e onze) são privadas e 296 (duzentas e noventa e seis) são públicas. Em 2016, 34.366 (trinta e quatro mil, trezentos e sessenta e seis) cursos de graduação foram ofertados

\footnotetext{
${ }^{4}$ As autoras do presente artigo não desconhecem a polêmica da discussão que envolvem o conceito "precariado", contudo, optou-se por desenvolver a abordagem em Giovanni Alves, sem desconsiderar o fato que existem outros autores que discutem a temática, como: Ruy Braga, Guy Standing e Jessé de Sousa.
} 
em 2.407 (duas mil, quatrocentos e sete) instituições de educação superior no Brasil. O número de matrículas na modalidade à distância continua crescendo, atingindo quase 1,5 milhão, o que já representa uma participação de $18,6 \%$ do total de matrículas da educação superior. Um dado significativo é que, em 2016, mais de um milhão e cem mil estudantes concluíram a educação superior.

De acordo com o levantamento da Coordenação de Aperfeiçoamento de Pessoal de Ensino Superior (Capes/MEC, 2016), o Brasil tem 122.295 (cento e vinte e dois mil, duzentos e noventa e cinco) estudantes de pós-graduação, dos quais 76.323 (setenta e seis mil, trezentos e vinte e três) são de mestrado acadêmico, 4.008 (quatro mil e oito) de mestrado profissional e 41.964 (quarenta e um mil, novecentos e sessenta e quatro) de doutorado. Nos últimos oito anos, o número de cursos de pósgraduação aprovados pela Capes têm crescido, em média, $9 \%$ ao ano.

Diante disso, compreende-se que a expansão geral da pós-graduação ocorre não só pelo aumento da oferta de cursos de pós-graduação, derivada de estímulos governamentais, mas, sobretudo, pelo aumento da demanda da sociedade por maior nível de escolarização, que se tornou uma exigência para o ingresso no mercado de trabalho, o que acabou por atrair o setor privado para a área educacional, devido à garantia dos seus investimentos com altas taxas de retorno sobre o capital (CIRANI, CAMPANARIO \& SILVA 2015, p.168).

Sendo assim, relaciona-se à questão do precariado com a expansão da educação superior, principalmente no que condiz com a entrada na pós-graduação, visto que "o conceito de precariado implica o cruzamento das determinações de ordem geracional, educacional e salarial" (ALVES, 2012). Para esse autor, o precariado se tornou um enigma, pois, ainda busca seu lugar dentro da sociedade do capital, sendo levado a perda de sua condição existencial por serem jovens/adultos altamente escolarizados e que possuem uma carga de expectativas, aspirações e sonhos de realização profissional e de vida plena de sentido (ALVES, 2013). Nota-se que a possibilidade de inserção qualificada por meio da pós-graduação passa a ser um "chamariz" e consequentemente tende a dar visibilidade ao conceito do precariado, sujeitos estes que buscam mecanismos para se inserir no mercado de trabalho e almejam a "tão sonhada" ascensão social. 
$E$ isso nos leva a refletir: vivemos em tempos de qualidade total ${ }^{5}$ na esfera do trabalho, e o precariado passa a ser visível. Nesse sentido, ao trabalhador, no processo de inserção no ensino superior, vende-se um discurso da qualificação, por meio da educação, com vistas à inserção ao mercado de trabalho. Contudo, essa é por vezes residual, provisória e precária. Desmontar esse discurso e despir essa roupagem do proletariado só será possível se problematizarmos o precariado, ou seja, a dimensão política desse conceito.

Os pressupostos anteriores demonstram a necessidade de se aprofundar na relação educação versus trabalho versus precariado, e isso terá como base teórica as discussões propostas por: Mészáros (2009), Giovani Alves (2007, 2012, 2013), bem como se alicerçando em levantamento documental: Ministério de Ciência e Tecnologia, Indicadores Nacionais de Ciência, Tecnologia e Inovação (1998-2012), Plano Nacional de Pós-Graduação - PNPG (2011-2020), dados do Relatório da PróReitoria de Pesquisa e Pós-graduação - Propesp (2016) vinculada a UFAM.

O artigo organiza a discussão em cinco partes que se complementam, quais sejam: a introdução que apresenta a temática; no Desenvolvimento se discute sobre a Crise Estrutural do Capital, bem como as categorias juventude e desemprego para introduzir a discussão do precariado; as considerações finais pontuam as aproximações sucessivas acerca do debate entre educação e trabalho. Posto isso, objetiva-se edificar um conhecimento que possibilite desvendar as tramas da crise estrutural do capital e o precariado?, com vistas a arquitetar estratégias de luta, pois se compreende que só se constrói "uma história de lutas e de resistência, apostando no futuro, mas entendendo que ele se constrói agora, no presente" (RAICHELIS, 2010, p.770).

\section{A CRISE ESTRUTURAL DO CAPITAL: QUE TEMPOS SÃO ESSES PARA A CLASSE TRABALHADORA?}

O sistema do capital é permeado por crises. Estas se apresentam ora em crises de curta duração, ora de longa duração, inerentes ao metabolismo de reprodução do capital na sua busca por acumulação. Com o advento da crise iniciada em 1973, o mundo do trabalho passa por transformações profundas, visto que a crise do capital enquanto um fato histórico não apresenta somente condicionamentos econômicos,

\footnotetext{
${ }^{5}$ Andrade (2017) sinaliza que o termo "qualidade total" visa aproximar todas as esferas da sociedade com o mercado, visto que se expande a crescente mercantilização que assola a sociedade global.
} 
mas também, elementos de ordem social e política (MANDEL, 1990). Sendo assim, como forma de superação a esse processo o capital busca se reestruturar, apresentando novos elementos de sustentação, apropriando-se da riqueza pública, por meio do sistema de dívida, da "chantagem" política aos governos com vistas a minimização do Estado Social. Contudo, isso não significa a extinção do Estado, mais a edificação de um Estado forte para assegurar as liberdades de mercado e residual para manter a proteção ao mundo do trabalho (ANDERSON, 1995).

Andrade (2017), apoiando-se em Ernest Mandel (1990, p.33-37), afirma que a sociedade capitalista é permeada de crises de curta e longa duração. Para tanto, esse autor pontua que "desde a formação do mercado mundial do capitalismo industrial houve exatamente vinte crises de superprodução, com intervalos mais ou menos regulares, São elas as de 1825, 1836, 1847, 1899, 1873, 1882, 1891, 1900, 1906, 1913, 1921, 1929, 1937, 1949, 1953, 1958, 1961, 1970, e a de 1974/75". Além da crise emblemática de 1975, concebida por Mandel (idem, p.73) como "resultado de todas as contradições fundamentais do modo de produção capitalista", tem-se nos anos de $2008^{6}$ outro ciclo de crise do capital ${ }^{7}$ que afeta de forma significativa os países de capitalismo tardio ou maduro ${ }^{8}$, espraiando-se para os países de capitalismo periférico ${ }^{9}$, como por exemplo, o Brasil.

No Brasil esse processo se potencializa nos anos de 1990. Em tempos de concentração de poder econômico que conduz a concentração de poder político revela-se o "caráter antidemocrático do capitalismo" (NETTO e BRAZ 2009, p.224). Neste entendimento, salienta-se que o "capitalismo contemporâneo particulariza-se pelo fato de, nele, o capital estar destruindo as regulamentações que the foram impostas como resultado das lutas do movimento operário e das camadas

\footnotetext{
${ }^{6} \mathrm{~A}$ crise financeira internacional teve seu desenrolar ao colocar em xeque a arquitetura financeira internacional, na medida em que explicitou as limitações dos princípios básicos do sistema de regulação e supervisão bancária e financeira atualmente em vigor, bem como pôs em questão a sobrevivência de um perfil específico de instituições financeiras. Andrade (2017 apud FARCHI; PRATES; FREITAS; CINTRA, 2009).

${ }^{7}$ Para Mészáros (2015) existe uma diferença fundamental entre as tradicionais crises cíclicas/conjunturais, como as elencadas por Mandel (1990) que são pertencentes à normalidade do capitalismo e a crise estrutural do sistema do capital como um todo, que define o atual período histórico. ${ }^{8}$ Boschetti e Behring (2008) com base em Mandel (1990) conceituam capitalismo tardio ou maduro como sendo um estágio do desenvolvimento capitalista onde as contradições e tendências de barbarização da vida social são aprofundadas devido ao caráter cíclico das crises do capitalismo, onde ondas de expansão e estagnação se alternam durante o tempo.

${ }^{9}$ Entende-se por capitalismo periférico, aquele "desenvolvimento desigual" (LÊNIN, 2003) provocado pelo excedente de capital dos países centrais em direção, por exemplo, aos países da América do Sul, e que incorpora o conceito de "desenvolvimento combinado" de Trótski (1980).
} 
trabalhadores" (idem, p.225).

As alterações contemporâneas no mundo do trabalho expressam a ofensiva neoliberal do capital sobre o trabalho, pois se desmontam direitos oriundos da expansão do período fordista/taylorista sob a égide do keneysianismo. É lícito afirmar que a reestruturação do capitalismo contemporâneo afeta não só a esfera produtiva, do trabalho, como também afeta as demais esferas da vida social, como por exemplo, a educação. Além do que em tempos de neoliberalismo a expansão da educação superior é construída a partir da seguinte racionalidade: 1. Ampliação do setor privado; 2. A privatização das Instituições de Ensino Superior públicas (LIMA, 2009).

Segundo INEP/MEC e Censo da Educação Superior (2012) revela que entre os anos de (1994 - 2009), nos dois mandatos de FHC e Lula, com a política de expandir o ensino superior, às matrículas nas instituições públicas cresceram $121 \%$, enquanto nas instituições privadas cresceram 356\%. As instituições privadas abocanharam 4,4 milhões, enquanto as instituições públicas receberam quase três vezes menos alunos, o que computou 1,5 milhões.

Sobre o aumento dos cursos de pós-graduação, estudos de Porto e Régnier (2003), com base nos dados do censo do Ensino Superior do INEP, informam que entre 1994 a 2001 ocorreu um crescimento de 31\% no número de alunos nos programas de mestrado; em relação a cursos de doutorado ocorreu um crescimento de $73 \%$. Além disso, a expansão de matrículas na pós-graduação teve seu ápice nas instituições federais e estaduais no período de 1994/1998.

Em 25 anos (1987 a 2012), o número de alunos titulados aumentou de 861 para 42.878 no mestrado, e os de doutorado cresceram de 385 para 13.912, até mesmo os Mestrados Profissionais, que foram oficialmente reconhecidos a partir de 1998, apresentaram taxa de crescimento de 98\% (1999 a 2012).

Com base no exposto é que se relaciona à questão do precariado com a expansão da educação superior, que como visto anteriormente se trata de um conceito que "[...] implica o cruzamento das determinações de ordem geracional, educacional e salarial" (ALVES, 2012). Além disso, a nova camada social do precariado se vincula historicamente à etapa de crise estrutural do capital e a hegemonia do capitalismo financeiro que vivenciamos na atualidade (ALVES, 2012), como o autor direciona a discussão em seus estudos.

Segundo o Relatório da Organização do Trabalho - Tendências Globais (2014, p.4): 
[...] calcula-se que em 2013 cerca de 74,5 milhões de jovens entre 15 e 24 anos tenham sido desempregados, quase um milhão do ano anterior. A taxa de desemprego mundial juvenil aumentou para 13,1 por cento, um valor três vezes maior do que a taxa de desemprego dos adultos. Na verdade, a relação entre o desemprego dos jovens e o desemprego dos adultos atingiu uma alta recorde, valores registrar particularmente elevados no Médio Oriente e Norte de África, bem como em alguns países da América Latina e do Caribe e Sul da Europa.

Para entender melhor esses dados, a Pesquisa Nacional por Amostra de Domicílios Contínua (Pnad Contínua) (2019) revelou que entre os 47,3 milhões de pessoas de 15 a 29 anos, $23 \%$ não estudam e nem trabalham. No segundo trimestre de 2018, a taxa de desemprego no grupo de 18 a 24 anos estava em $26,6 \%$ - mais que o dobro da média geral do país no mesmo período (12,4\%). Quanto ao nível de escolaridade o Censo 2010 assinala que apenas $16,2 \%$ dos jovens de todo o país chegaram ao ensino superior, $46,3 \%$ apenas concluíram o ensino médio e $35,9 \%$ têm sua escolaridade limitada ao ensino fundamental.

A expansão da educação superior no Brasil inexoravelmente se constitui em um processo relacionado com a visibilidade do precariado em nosso país. O que se objetiva ao relacionar o processo expansionista da educação superior com a visibilidade do precariado brasileiro reside no entendimento que essa visibilidade e reconhecimento político dependem da correlação de forças presentes em nossa sociedade. Dito isso, assegura-se que a criação de [...] um tecido social em torno de uma problemática com capacidade de inseri-la no debate político, o que o projeto neoliberal vota contra (WANDERLEY, 1997, p.57).

Sustenta-se que a política educacional de ampliação mais expressiva do acesso ao sistema de ensino superior, bem como do ensino técnico dá-se a partir da expansão das instituições no período de 2003 a 2010. Além disso, no período de 2007 a 2010 tem-se o lançamento do Programa de Apoio a Planos de Reestruturação e Expansão das Universidades Federais, o REUNI, que objetiva assegurar o acesso e permanência na educação superior. Importa destacar que "o REUNI é também uma proposta de atender às diversas reivindicações de várias entidades, de segmentos e setores importantes de nossa sociedade".

Andrade (2017), ao refletir acerca das medidas de políticas públicas de acesso à educação superior, calça-se em Ferreira (2012), e argumenta que a reforma da educação superior efetivada no governo Lula optou pela continuidade de várias diretrizes adotadas pelo governo $\mathrm{FHC}$, ao priorizar como papel fundamental das universidades a perspectiva do seu retorno econômico para a sociedade brasileira; ao 
incentivar a diferenciação e a competição das universidades federais por recursos e na gestão estratégica; ao apoiar parcerias público-privadas, inovação tecnológica e venda de serviços; ao conferir centralidade aos sistemas de avaliação e regulação.

O processo de expansão da educação superior é uma luta histórica em nossa sociedade. E essa expansão é potencializada pelo ethos atual que propugna a relação entre educação superior e trabalho, pois emerge com vigor bem ao gosto do neoliberalismo, teorias que promovam a vinculação entre educação e crescimento econômico, o que potencializa o vigor do capital pela "mercadoria" educação e isso ocasiona um redimensionamento da política educacional em nosso país.

O redimensionamento da política educacional brasileira, colocada em movimento pelos governos neoliberais brasileiros, expressada sob o prisma do processo de contrarreforma do Estado, visa também reformar a educação superior. Alves (2013, p.35) afirma que "ao debruçarmos sobre os Planos, medidas e ações que se tem para a educação desde a década de 1990, pois [...] de Collor de Melo a Itamar Franco, passando por Fernando Henrique Cardoso, Luís Inácio Lula da Silva e Dilma Rousseff, guardando as devidas proporções, relativas ao tempo histórico e viés de cada governo, em maior ou menor intensidade, atende aos ditames do grande capital (ALVES, 2013, p.35). Sob o "Toque de Midas" dos organismos internacionais, leia-se: - Banco Internacional para Reconstrução e Desenvolvimento (BIRD); o Banco Mundial; a Organização das Nações Unidas para a Educação, a Ciência e a Cultura (UNESCO), as regras para a educação superior no Brasil passam a serem ditadas e implementadas em nome de uma pretensa modernidade.

A reengenharia educacional promovida desde os anos de 1990 no sistema de ensino superior, nos dizeres de Alves (2007), constitui-se na exigência de novas ou metamorfoseadas qualificações ${ }^{10}$ que compõem a nova subsunção real do trabalho ao capital, o que nos leva a ratificar que aparece inconteste, nesta "geopolítica do capital em crise" (CARVALHO E GUERRA, 2015), a condição de vida e trabalho dos jovens que conformam o precariado, constituindo-se elemento importante para apreensão da dinâmica social (NASCIMENTO, GUERRA \& TRINDADE, 2016, p.5-6).

\footnotetext{
10 A reengenharia no campo educacional é "geradas pela reorganização produtiva no âmbito das instituições capitalistas" (LIBÂNEO; OLIVEIRA; TOSCHI, 2005, p. 35). Sob a batuta dos organismos internacionais o que se propugna para países da América Latina, inclui-se o Brasil, um processo de qualificação por meio do investimento em educação, visando o desenvolvimento econômico e não ao desenvolvimento das pessoas.
} 


\section{A JUVENTUDE E O DESEMPREGO.}

O desemprego entre os jovens vem sendo sentido de forma dramática, visto que essa faixa etária sofre discriminação do setor produtivo, decorrente de sua pouca experiência, baixa produtividade e alta rotatividade. Para tanto, é necessário problematizar a questão do desemprego entre os jovens, pois conforme dados da Pesquisa Nacional por Amostra de Domicilio - (Pnad) trimestral do IBGE (2019) dos mais de 13 milhões de desempregados no país em 2019, 32\% têm entre 18 e 24 anos, o que corresponde a um contingente de 4,1 milhões de jovens nesta faixa etária em busca de emprego. Este número é superado apenas pelos trabalhadores com idade entre 25 e 39 anos, que correspondem a $34,6 \%$ do total de desempregados, cerca de 4,5 milhões. Colaborando com essa informação, a Organização Internacional do Trabalho (2017) afirma que a taxa de desemprego entre os jovens é a maior em 27 anos, cerca de $30 \%$ de pessoas entre 15 a 24 anos buscam formas de ocupação, esclarece ainda que a taxa brasileira é mais que o dobro da média mundial, de 13,1\%.

Segundo Martins (2017, p.7) analisando a atual situação brasileira: "[...] muitos jovens conseguem se formar, porém não conseguem garantir um emprego". Um artigo sobre o assunto escrito pela OIT, diz que o fato de jovens não conseguirem um bom emprego faz com que esta era de recém-formados se chame de "geração perdida". Observa-se, contudo, que a busca por qualificação via escolarização, a qual é vista como uma preparação para entrada no mundo do trabalho, não garante que estes sujeitos adentraram o mercado de trabalho e se o fazem, em parcela significativa, são em relações de trabalhos instáveis e precários.

Atrelado a este contexto tem-se o desejo dos jovens em dispor de possibilidades de mobilidade social, o que coaduna com a afirmação de Alves (2013, p.199): "à condição de proletariedade do jovem interfere em sua condição existencial universal no mundo social do capital em sua face de crise estrutural, interferindo diretamente na irrealização estrutural das promessas civilizatórias do capital, por meio da busca pela qualificação".

No Amazonas a situação do jovem quanto à inserção no mundo do trabalho segundo pesquisa do DIEESE (2012), mostra que na relação: "[...] trabalho e estudo simultâneos também registrou diminuição percentual dos jovens, com redução de $71,0 \%$ para $67,9 \%$ da população com mais de 14 anos de idade. Entre aqueles que 
apenas trabalham, em 2001, 35,1\% eram jovens; já em 2009 foram 29,3\%, com uma redução de mais de 5 p.p na participação do grupo jovem nessa situação de trabalho."

Para Oliveira (2012), o conceito de qualificação para o trabalho, presente no discurso empresarial, tal como se observou nas empresas estruturadas relacionadas ao posto de trabalho, o trabalhador qualificado é aquele cujo perfil atenda ao trabalho requerido para atividades estritas do posto. Logo, a busca pela qualificação via escolarização tende a não atender às necessidades estabelecidas pelo capital em países de capitalismo periférico. Segundo Nunes (2015, p. 66): "[...] não se pode afirmar que a política de trabalho para juventude brasileira encontra-se consolidada, o que existe são diferentes ações e programas executados visando combater o desemprego entre os jovens, seja prolongando sua permanência na escola ou incentivando sua qualificação profissional para posterior ingresso no mercado de trabalho".

Quantificando a questão do desemprego na região norte que vem crescendo devido ao processo de reestruturação produtiva que atingiu o Pólo Industrial de Manaus - (PIM) desde os anos de 1990, desacelerando suas atividades, achatando os salários e introduzindo novas tecnologias, revela-se de acordo com o gráfico abaixo:

Gráfico 1: Participação relativa das pessoas de 14 a 29 anos no mercado de Trabalho - Região Norte.

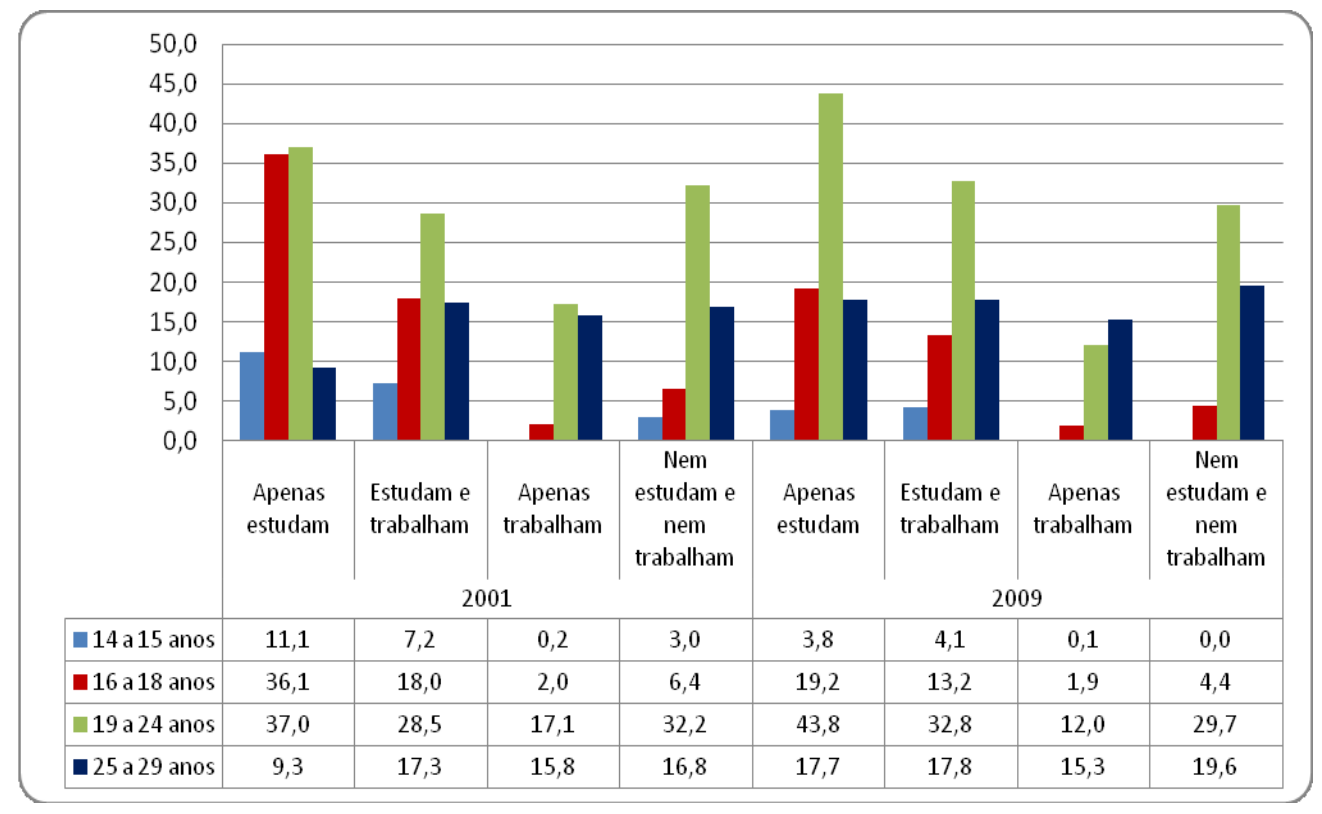

Fonte: Pnad/IBGE. (2011) 
O gráfico expõe uma categorização acerca da participação dos jovens no mercado de trabalho, na Região Norte, demonstra a participação dos jovens de acordo com o grupo etário em atividades e a relação entre trabalho e estudo. Nunes (2015, p. 56) afirma que "atualmente, temos um problema acentuado, pois, de um lado existe um contingente imenso de desempregados trabalhando para conseguir emprego, e de outro, trabalhadores empregados trabalhando muito mais do que antes. Este cenário causa uma grande insegurança na sociedade em relação ao mundo do trabalho". No que se refere à escolarização dos jovens da Região Norte por grau de escolaridade, o gráfico a seguir demonstra:

Gráfico 2. Distribuição percentual das pessoas de 14 a 29 anos segundo o grau de escolaridade. Amazonas, (2001 e 2009).

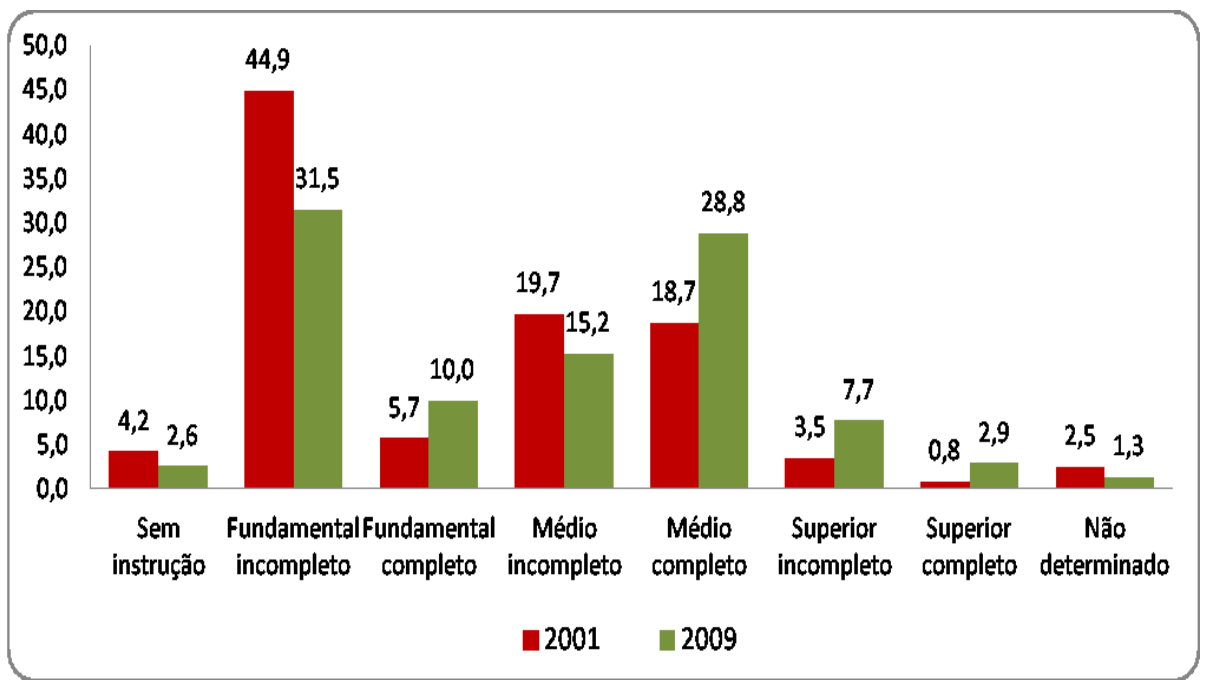

Fonte: Pnad//BGE (2011)

O gráfico reflete um incremento substancial na participação dos jovens de 14 a 29 anos no total de pessoas que possuem 'Superior incompleto' e 'Superior completo'. Assim, em 2009, do total de pessoas na população amazonense que possuíam escolaridade declarada de 'Superior incompleto', 61,9\% eram jovens, além do que em 2001 tinha-se um percentual de 49,2\%. O mesmo ocorreu com as pessoas que declararam escolaridade 'Superior completo'; em 2001, 15,6\% eram jovens, em 2009 essa participação cresceu 5,5 pontos percentuais indo para $21,1 \%$ de jovens.

O "chamado" para o ingresso no ensino superior tem se constituído em uma possibilidade para que o expressivo segmento de pessoas desempregadas, bem como para que jovens em situação de desemprego busquem assegurar a inserção no mercado de trabalho pela via do aumento da escolarização. Porém, a inserção no ensino superior não é "passaporte" para a entrada ou manutenção desses sujeitos no 
mercado de trabalho, pois muitas vezes ter nível superior constitui-se num critério de elegibilidade para vagas cuja ocupação não necessitaria de um profissional de nível superior, muito menos pós-graduado para ocupá-la. Por vezes, isso pode se tratar de engodo que o mercado propaga para vender a mercadoria educação.

Nesse ponto é que se faz a correlação da expansão da educação superior, em especial da pós-graduação que de 1976 a 2012 teve uma evolução de 174,6\% por década (CAPES, 2012) com a visibilidade da categoria precariado em nosso país. Para tanto, objetiva-se com essa reflexão incursionar acerca do seguinte questionamento: a expansão da educação superior, em especial da pós-graduação, constitui-se essencialmente em uma democratização do ensino com vistas ao desenvolvimento científico, tecnológico e social do país ou se constitui em essência, como reflete Giovani Alves (2012), em incubadoras do precariado em nosso país?

Para provocar a reflexão acerca desse questionamento, o artigo publicado na Revista Galileu, intitulado "O que você precisa saber sobre a pós-graduação no Brasil" (2017), de autoria de Thiago Tanji, explicita que a taxa de empregabilidade de mestres e doutores (em porcentagem) variam de acordo com a área de conhecimento escolhida, e ainda

[...] a necessidade de fazer especialização ou aprimoramento - como eles dizem. Enfim, uma pós-graduação capaz de lhes garantir a dita "empregabilidade": "Para ter um bom emprego, você precisa estar se atualizando, continuar se aprimorando, para ter uma boa oportunidade". Mas a escolha do aprimoramento continuado ou cursos de especialização e pósgraduação tornou-se a versão atual do alongamento da escolarização, não apenas como a alternativa mais recorrente dos jovens diante do desemprego, mas como necessidades de qualificar-se melhor para acesso a certos postos de trabalho melhor remunerados, que não são para todos (ALVES, 2013, p. 247).

Contudo, isso se realiza? Ou constitui-se em um "canto da sereia" sob os ditames do projeto neoliberal?. Para Giovanni Alves (2012, p. 02), esses jovens que compõem a complexa expansão do ensino superior possuem características do que o autor denomina como precariado: "[...] é expressão do sistema social da produção do desperdício generalizado: desperdiça-se a futuridade de jovens altamente escolarizados, penhorando-se suas perspectivas de carreira e mobilidade social". Logo, vive-se um novo tempo nos desmontes dos direitos sociais, a quebra do pacto social e implantação do trabalho flexível em troca de uma falsa ilusão de empregabilidade sem benefício ou direito, o que sobra aos trabalhadores é o medo que rodeia a mais fina camada que passa a ter visibilidade: o precariado. 


\section{AFINAL, O QUE É PRECARIADO?}

Ratifica-se, que o precariado não é uma classe social e sim a camada social do proletariado, constituída por um contingente de proletariado que está despossuída de propriedade, estão desempregados e/ou inseridos em relações de trabalhos instáveis (ALVES, 2012). Essa camada do proletariado tem em seu bojo a apartação da cidadania e da relação do emprego estável, e tal situação se dá dentro do seio da crise estrutura do capital.

No Brasil, esse perfil populacional começa a ter visibilidade a partir da década de $1980 \mathrm{com}$ a entrada do modelo de produção industrial toyotista que propunha flexibilizar o mercado e o processo de trabalho, e por consequência isso refletirá de forma negativa na proteção social dos trabalhadores.

É importante salientar que no Amazonas, segundo Oliveira (2003, p. 07), no

PIM o enxugamento de postos de trabalho, caminhou em sintonia com a tendência nacional do mercado de trabalho brasileiro na década de 1990. A evolução dos índices de desemprego foi, em grande medida, determinada pela indústria eletroeletrônica, e teve como base a eliminação de grande número de linhas de montagem manual $e$, sua substituição por equipamentos nas áreas de inserção automática (OLIVEIRA, 2003, p. 07)

Essa desregulamentação de direitos atinge de forma incisiva os jovens que vivenciam a precariedade salarial, que se baseia no trabalho flexível e reestruturado. Estes que visam por meio da "qualificação", ligado ao discurso da competência, entrar no mercado de trabalho, se vêem destituídos de possibilidades e inseridos em condições precárias e/ou de desemprego, sendo assim:

[...] a nova dinâmica do mercado de trabalho no Brasil na década de 2000
faz com que um contingente de jovens altamente escolarizados fique
desempregado ou inserido em relações salariais precárias tendo em vista a
degradação do estatuto salarial (por exemplo, contrato precário de trabalho e
baixa remuneração salarial). Por exemplo, segundo o jornal "O Estado de São
Paulo" de $30 / 06 / 2013$, o salário médio mensal dos trabalhadores com mais
anos de escolaridade recuou entre 2002 e 2011 no Brasil. A média de salário
dos profissionais com 12 anos ou mais de estudo caiu $8 \%$ nesse período, de
R $\$ 3.057$ para $R \$ 2.821$ (a variação já desconta a inflação do período). Isso
significa que o poder aquisitivo desse grupo caiu em 10 anos (ALVES, 2012
p. 02 ).

Essa nova dinâmica do mercado de trabalho vem sendo sentida principalmente por conta dos altos níveis de desemprego e/ou trabalhos precários. Alves (2012) afirma que esses jovens se encontram dentro de um sistema laboral que possui algumas características peculiares, quais sejam: 1. Um novo arcabouço tecnológico informacional; 2. A vigência do espírito do Toyotismo; 3. A renovação geracional dos coletivos de trabalhos; 4 . As relações de trabalho flexível. Essas características dão 
tonalidade à nova morfologia do trabalho e agudiza a precariedade salarial, impondo à juventude a busca por escolarização com o ideário de alcançar a ascensão social e econômica, induzindo assim ao fetiche do consumo.

Atualmente, em especial, a busca pela educação superior se tornou um caminho para o possível acesso ao tal sonho de futuridade e consumo. Sguissardi (2006) afirma que o capital com intuito de acumular viu na expansão da educação superior a possibilidade de ampliação no setor privado em sintonia com a lógica de acumulação e reprodução do capital.

Vale destacar que, a partir dos anos de 1990, verifica-se uma taxa contínua e muito baixa de escolarização líquida da população brasileira de 18 a 24 anos: 14,4\% (CENSO/INEP, 2010), bem como $74 \%$ das matrículas nos cursos de graduação encontram-se nas Instituições de Ensino Superior Privado, sendo o setor público responsável por $26 \%$ dessas matrículas. (INEP, 2010). Diante deste cenário, Alves (2012, p.03) acredita possuir elementos para afirmar que as universidades públicas e privadas, são incubadoras do precariado.

Nesta direção, reflete-se que a alta escolarização não possibilitará, em termos, a entrada do jovem/adulto no mundo do trabalho e/ou em empregos precários. O que se percebe é um grande número de jovens que não veem alternativa senão continuar "remando" em direção a outras possibilidades como a pós-graduação lato sensu e strictu senso no intuito de obter mais possibilidade para competir no mercado de trabalho. Alves (2012, p. 3) em um curta metragem denominado Galera (2012) traz a fala de um jovem recém-formado: "[...] quem sabe, tentar a pós-graduação, porque hoje, com o diploma, não é igual há trinta anos, quando você tinha mais chance; era uma pessoa mais seleta que hoje. (...) hoje o mercado leva você a essas especializações que demandam muito sempre da pessoa".

A competição imposta pelo capital induz o jovem a buscar mais escolarização como forma de se inserir, o medo do desemprego e falta de condições tende a forçálo a continuar estudando e sonhando em ascender social e principalmente economicamente. Daí a hipótese de que a expansão da educação superior, em especial da pós-graduação, constitui-se em um processo de democratização do acesso ao ensino superior, o que tende a dar visibilidade a camada social do precariado no Amazonas na medida em que esses jovens altamente escolarizados se inserem - durante ou após a titulação - em ocupações precárias ou ficam desempregados, frustrando suas expectativas de realização profissional. 
Dados retirados de levantamento documental computados no relatório da PróReitoria de Pesquisa e Pós-graduação - (Propesp) da Universidade Federal do Amazonas - UFAM, sobre a pós-graduação strictu senso (mestrado e doutorado) demonstra a entrada por meio de processo seletivo nos anos de 2000 a 2016 de 3.199 (três mil cento e noventa e nove) alunos nos mais diferentes cursos de pós-graduação. Dentre esse universo, existe um quantitativo de 1.106 alunos formados, sendo 847 mestres e 259 doutores no período de 2000 a 2016, dos mais variados cursos, abaixo o gráfico evidencia os dados:

Gráfico 3: Quantitativo de alunos formados por curso de Pós-graduação da UFAM - 2010 a 2016.

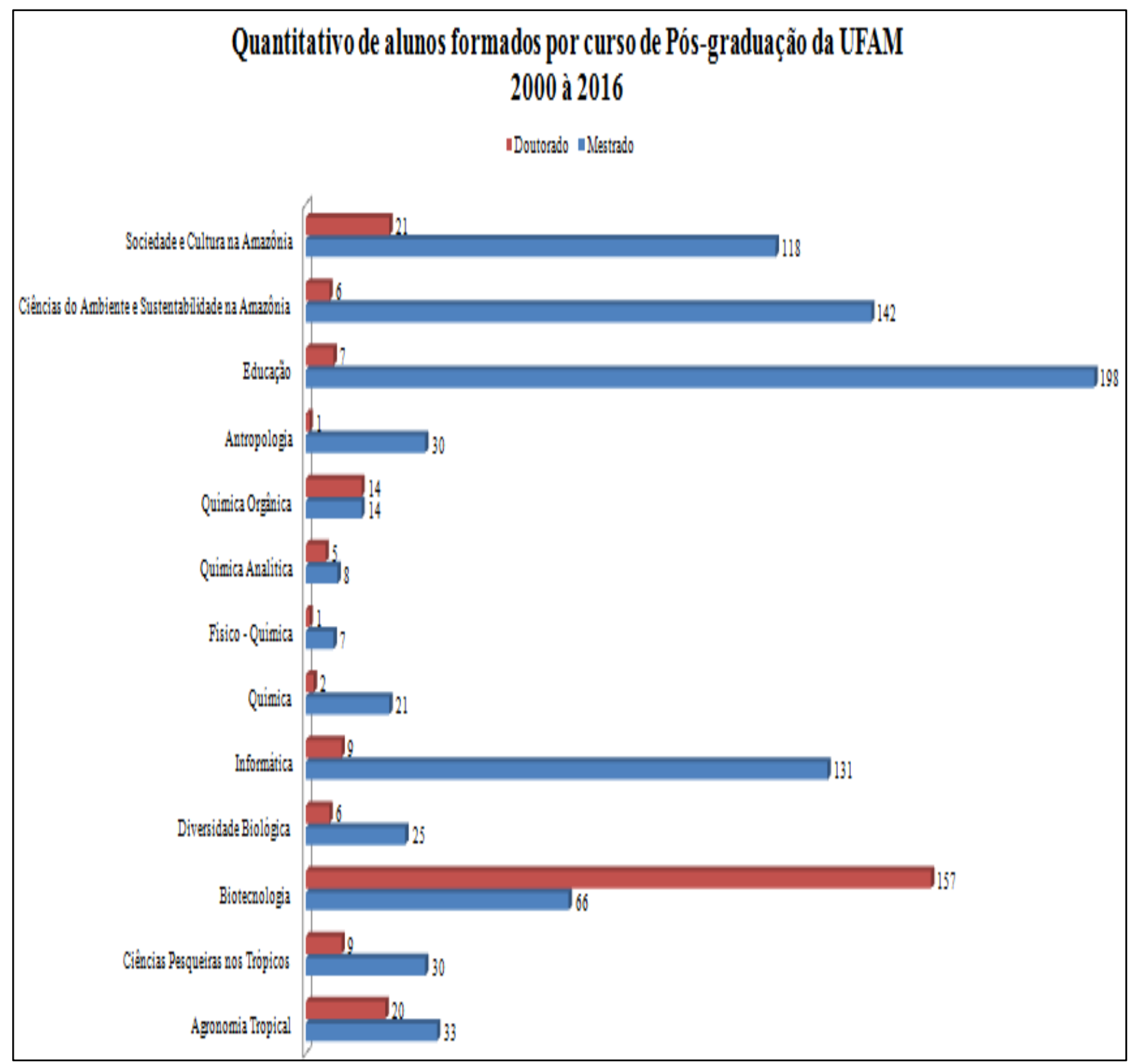

Fonte: Pesquisa documental, dezembro de 2016.

A análise do aumento da pós-graduação em nosso país relaciona-se a proposta de desenvolvimento futuro, bem como a funcionalidade do ensino superior brasileiro, 
além do que ao se falar sobre ensino superior de pós-graduação está se falando da oferta dessa modalidade de ensino pelas universidades, mas se sabe que essa oferta não é exclusiva delas. Quando se observa o gráfico 02 os cursos de pós-graduação mais demandados nas IFES são educação e biotecnologia. Argumenta-se que a procura desses cursos condiz com o fato de que o ensino da pós-graduação se constitui "na instância mais forte na formação do docente/pesquisador e do cientista" (CASSIANO SILVA 2009, p.298)

É importante destacar que a procura pela pós-graduação muitas vezes é vista como necessidade do jovem, pois ele busca se escolarizar devido aos anseios de melhor possibilidade de vida, mais expectativa de ascensão, a procura pela aceitação e mobilidade social tendo como base o status de ter "vencido na vida".

Nota-se que tal busca está ligada, segundo Alves (2012, p. 06), a:

[...] dar sentido à ação instrumental na pseudoconcreticidade da vida quotidiana de jovens proletários sonhadores, ansiosos e pragmáticos, que o mantra do capital humano se perpetue, não mais validando a aquisição do emprego por toda a vida, mas sim a capacidade de empregabilidade em trajetórias ocupacionais intermitentes, liminarmente precárias (ALVES, 2012, p. 06).

Com base na assertiva acima e as profundas transformações que vêm ocorrendo na esfera produtiva, ou seja, no mundo do trabalho, discutir acerca do processo em curso e suas inflexões na categoria trabalho têm a intenção de dar densidade a um conceito que se constrói de forma dialética e em sintonia com a realidade, que é dinâmica, histórica e processual.

\section{CONSIDERAÇÕES EM PROCESSO...}

Esse ensaio longe de apresentar respostas constitui-se em uma possibilidade ou seria melhor dizer em uma pretensão? Ousa-se problematizar a relação entre expansão da pós-graduação com a visibilidade do precariado. Assim, revitaliza-se a velha máxima "diga onde está o trabalho na sociedade e eu te direi onde está a educação".

A incursão teórica, por meio de aproximações sucessivas, acerca da crise estrutural da capital, desemprego estrutural e precariado, permite-nos afirmar que a educação no atual momento histórico mais do que se constituir em uma possibilidade de emancipação humana encontra-se sob a regência do capital e se transmuta em 
uma mercadoria barata, de fácil consumo e de conteúdo aligeirado, se espraiando dessa forma em todos os níveis do Sistema de Ensino Brasileiro.

Com a atual expansão do ensino superior, verifica-se que a ilusão do desenvolvimento se realiza sob o signo da democratização do acesso à educação superior no Brasil. Somos cientes de que esse processo de expansão é necessário diante da dívida social que se tem com os segmentos subalternizados em nosso país, contudo, é vital refletir de forma crítica acerca da qualidade desse processo de expansão.

Refletir acerca da relação entre expansão da pós-graduação e a visibilidade do precariado reside no entendimento de que a qualificação profissional e as exigências para que o trabalhador se capacite constitui-se em um ethos na atualidade tendo no seu avesso o aumento exponencial do desemprego, enquanto estratégia do capital, em meio a sua crise de valorização do valor, e isso ocasiona inflexões na esfera dos direitos da classe trabalhadora, os quais necessitam colocar à disposição do mercado sua força de trabalho para sobreviver e, mais especificamente, para aqueles que se encontram inseridos no exército industrial de reserva, com destaque para o "precariado". Esses jovens têm vivenciado toda a sorte de desproteção trabalhista e de instabilidade pessoal e profissional (TRINDADE, 2017).

Por fim, o desvendamento entre a expansão da educação superior, em especial da pós-graduação com a visibilidade da camada social do precariado possibilita refletir como se dá a subsunção do trabalho pelo capital em tempos de capital financeiro, crise estrutural e de desmonte de direitos sob a égide do projeto neoliberal, na busca por estratégias que façam a reversão do processo em curso que teima em aniquilar utopias, com vistas a retomada da rentabilidade inerente ao seu modus operandi e avesso à emancipação humana. 


\section{REFERÊNCIAS}

ALVES, G. Dimensões da precarização do trabalho: ensaios de sociologia do trabalho. Bauru: Canal 6, 2013.

ALVES, G.Toyotismo Como Ideologia Orgânica da Produção Capitalista. RET Rede de Estudos do Trabalho, UNICAMP, Ano I, nº 1, Campinas, 2007.

ALVES, G. A revolta do precariado no Brasil. [S. I.: s. n.], 2012 a. Disponível em: https://blogdaboitempo.com.br/2013/06/24/a-revolta-do-precariado-nbrasil/ Acesso em: 05 jul.2019.

ANDRADE, M. I.P. ENTRE SOMBRAS E LUZENTES: o trabalho docente em tempos de intensa mercantilização do Ensino Superior. FACED/PPGE. UFAM. Mimeo, Manaus/Am, 2017. Tese de doutorado.

ANDERSON, P. Balanço do Neoliberalismo. In: SADER, Emir. (org.) Pósneoliberalismo - As políticas Sociais e o Estado Democrático. São Paulo: Editora Paz e Terra, 1995. p. 17-29.

BEHNING, E. R. \& BOSCHETTI, I. Política social: fundamentos e história. 9. ed. São Paulo: Cortez, 2008. (Biblioteca Básica do Serviço Social; v.2) BRASIL.

MEC/INEP. Censo da Educação Superior. INEP, 2012.

MEC/INEP. Censo da Educação Superior. INEP, 2010.

MEC/SEMESP. Mapa do Ensino Superior no Brasil. SEMESP, 2015.

CIRANI, C. B. S; CAMPANARIO, M. A H.; SILVA, H. M. A evolução do ensino da pós-graduação senso estrito no Brasil: análise exploratória e proposições para pesquisa. Campinas: Sorocaba, 2015.

DIEESE - DEPARTAMENTO INTERSINDICAL DE ESTATÍSTICA E ESTUDOS SOCIOECONÔMICOS. Juventude e Trabalho: Inserção Produtiva dos jovens no mercado de trabalho de Manaus nos anos 2000. Termo de Contrato $n^{\circ}$. 005/2011 SEMTRAD e DIEESE. Observatório do Trabalho, 2012. 
Instituto Brasileiro de Geografia e Estatística (IBGE). Censo 2010: síntese do desemprego. Rio de Janeiro, 2010a. Disponível em:

https://censo2010.ibge.gov.br/noticias-

censo.html?alvo=taxa\&busca=1\&id=3\&pagina=1\&paginar=1\&view=noticias Acesso em: 01 nov. 2018.

LIBÂNEO, J. C.; OLIVEIRA J. F.; TOSCHI M. S.; Educação escolar: políticas estrutura e organização. $2^{a}$ ed. São Paulo: Cortez, 2008. (Coleção Docência em Formação.

LIMA, Kátia. Contra-reforma (sic) da educação nas universidades federais: 0 REUNI na UFF. 2009. Disponível em:

https://cassmariaclenilda.files.wordpress.com/2013/04/20090917 contra-reforma.pdf Acesso em: 20 nov. 2018.

LÊNIN, V. I. Imperialismo, fase superior do capitalismo. Tradução: Sílvio Donizete Chagas. $2^{\circ}$ Ed. São Paulo: Centauros, 2003.

MARTINS, A. C. DE O. As causas do desemprego dos jovens no Brasil são semelhantes às observadas no mundo? 2007. Trabalho elaborado de acordo com as exigências do XI Prêmio de Ensaios Econoteen. Disponível em: http://www.econoteen.fea.usp.br/sites/default/files/ensaios/anderson.pdf Acesso em 07 fev. 2017

MÉSZÁROS, I. A crise estrutural do capital. São Paulo: Boitempo, 2009.

MANDEL, Ernest. A Crise do Capital: Os Fatos e sua Interpretação Marxista. São Paulo: Ensaio, 1990.

NASCIMENTO, L. A.; GUERRA, E. C. ; TRINDADE, H. Formação profissional e ensino superior em Tempos de crise do capital e de precarização do Trabalho: dilemas e reflexões em torno da Conformação do precariado no Brasil. Anais $X$ Seminário do Trabalho - Trabalho, Crise e Políticas Sociais na América Latina - 23, 24 e 25 de maio de 2016 - UNESP/Marília.

NETTO, J. P; BRAZ, M. Economia política: uma introdução crítica. 2. ed. São Paulo: Cortez, 2009.

NUNES, M. B. de A. Juventude e trabalho: uma análise da implementação do Programa Projovem Trabalhador no município de Manaus. 2015. Dissertação 
(Mestrado em Serviço Social) - Faculdade de Serviço Social, Universidade Federal do Amazonas, Manaus, 2015.

Human Development Report 2014. Relatório da Organização do Trabalho Tendências Globais. (2014). Disponível em:

http://www.br.undp.org/content/dam/brazil/docs/RelatoriosDesenvolvimento/undp-brHDR16\%20Report.pdf. Acesso em: 24 nov. 2018.

SGUISSARD, V. Modelo de expansão da educação superior no Brasil:

predomínio privado/mercantil e desafios para a regulação e a formação universitária.

Campinas: Educação e Sociedade, 2006.

OLIVEIRA, S. S. B. As Mutações no Processo Produtivo da Indústria Eletroeletrônica e a Qualificação dos Trabalhadores. 26 Reunião Anual da ANPED, 2003, Poços de Caldas. Novo Governo/Novas Políticas. Rio de Janeiro.

OLIVEIRA, S. S. B. de. A "periferia" do capital: na cadeia produtiva de eletrodomésticos. EDUA/UFAM, 2012.

PESQUISA NACIONAL POR AMOSTRA DE DOMICÍLIOS - PNAD. Taxa média de desemprego no Brasil (2016). Disponível em:

https://agenciadenoticias.ibge.gov.br/agencia-sala-de-imprensa/2013-agencia-denoticias/releases/19756-pnad-continua-taxa-de-desocupacao-e-de-11-8-notrimestre-encerrado-em-dezembro-e-a-media-de-2017-fecha-em-12-7 Acesso em: 07 fev 2019.

PORTO, Claúdio; RÉGNIER, Karla. O Ensino Superior no Mundo e no Brasil Condicionantes Tendências e Cenários para o Horizonte 2003-2025: uma abordagem exploratória. Disponível em:

http://portal.mec.gov.br/sesu/arquivos/pdf/ensinosuperiormundobrasiltendenciascena rios2003-2025.pdf Acesso em: 02 Dez. 2018.

TANJI, T. O que você precisa saber sobre a pós-graduação no Brasil. (2017). Disponível: https://revistagalileu.globo.com/Revista/noticia/2017/08/o-que-voceprecisa-saber-sobre-pos-graduacao-no-brasil.html Acessado em: 10 de jan. de 2019.

WANDERLEY, L. E. W. (2004, $2^{\text {a }}$ Ed.) A questão social no contexto da globalização: o caso latino-americano e o caribenho. Em L. Bogus, M. C. Yazbek \& M. Belfiore-Wanderley (Orgs.), Desigualdade e a questão social. São Paulo:

Educ., 2004. 